\title{
A reduction of ECS-produced amnesia through post-ECS sensory isolation
}

\author{
CHARLES F. HINDERLITER \\ Kent State University, Kent, Ohio 44242
}

and

\author{
SARAH L. SMITH and JAMES R. MISANIN \\ Susquehanna University, Selinsgrove, Pennsylvania 17870
}

\begin{abstract}
Previous research has shown that, following training-ECS treatments, rats kept in a sensory isolation chamber during the entire retention interval show little evidence of retrograde amnesia. In this experiment, rats trained on a passive avoidance task and kept in a sensory isolation chamber for only $1 \mathrm{~h}$ after training-ECS treatments also showed attenuated amnesia. In contrast, retrograde amnesia was complete in animals similarly trained but returned to home cages immediately after ECS. These results indicate that environmental manipulations within the first hour after training-ECS treatments can alter the amnesic effect of ECS, suggesting that critical events determining whether or not retrograde amnesia is produced may occur within that time period.
\end{abstract}

Numerous reports have substantiated the finding that the amnesic effect of treatments such as electroconvulsive shock (ECS) can be experimentally attenuated (e.g., Hinderliter, Smith, \& Misanin, 1973; Lewis, Miller, \& Misanin, 1968, 1969). First attempts at attenuating amnesia involved behavioral manipulations before the training amnesic-agent treatments (e.g., Lewis et al., 1968, 1969). More recently, several authors have reported that environmental manipulation can also attenuate retrograde amnseia (RA). Calhoun, Prewett, Peters, and Adams (1975), for example, reported that merely keeping rats in darkness during the ECS retention interval can reduce ECS-produced RA. Similarly, Misanin and Hoover (1971) reported that an environment that leads to slow recovery from hypothermia, as indexed by rectal temperature, attenuates the RA in rats that typically follows severe hypothermia (e.g., Riccio, Hodges, \& Randall, 1968).

The above studies, as well as others (e.g., Peters, Calhoun, \& Adams, 1973; Smith \& Misanin, 1972) indicate that events following the training amnesiacagent treatments, as well as those preceding, can attenuate the deleterious effect of amnesic agents on retention. How long after administration of the amnesic agent environmental events are capable of such attenuation, however, has not been determined. Since recovery to near normal temperature occured in about $90 \mathrm{~min}$ in rats not showing RA in the Misanin and Hoover (1971) study, it would appear that events within 1 or $2 \mathrm{~h}$ after treatment are the most significant. Because the previous experiments dealing with sensory isolation and ECS involved isolation over the entire

Requests for reprints should be sent to James R. Misanin, Department of Psychology, Susquehanna University, Selinsgrove, Pennsylvania 17870.
ECS retention interval (Calhoun et al., 1975; Peters et al., 1973), it seemed important to determine if a relatively short period of sensory isolation would have a similar attenuating effect on RA. It also seemed important to attempt to clarify the role illumination plays in the attenuation of ECS-produced RA. In the Calhoun et al. (1975) and Peters et al. (1973) ECS-isolation studies, the animals were kept in constant light for 60 days prior to the start of the experiment; hence, novelty produced by a change in illumination rather than sensory attenuation produced by darkness may have been partially responsible for the reduction of RA. Thus, the present experiment sought to examine further the effect of sensory isolation on ECS-produced RA by confining rats to a sensory isolation chamber for only $1 \mathrm{~h}$ following ECS rather than for the entire ECS retention interval. In addition, to eliminate novel illumination changes as a factor in any attenuation of RA that might obtain, the animals used in this experiment were on a day/night cycle from birth rather than on the 24-h-day light regimen used in previous studies.

\section{METHOD}

\section{Subjects \\ Sixty $125-$ to $210 \mathrm{~g}$ female albino rats of the Wistar strain, born and reared in the Susquehanna University animal colony, were used. Until a week before training, all animals had been group housed with ad lib food and water. A week before train- ing, all subjects were individually caged and given $10 \mathrm{~g}$ of Purina Lab Chow daily and free access to water. The animal colony was maintained on a 14-h day and 10-h night cycle at all times.}

\section{Apparatus}

The training apparatus consisted of a $51 \times 51 \mathrm{~cm}$ grid floor enclosed by $61-\mathrm{cm}$-high transparent acrylic walls. The grids were 5-mm-diam steel rods spaced $19 \mathrm{~mm}$ apart center to center. A $10 \times 12.7 \mathrm{~cm}$ platform located $7.6 \mathrm{~cm}$ above the center of 


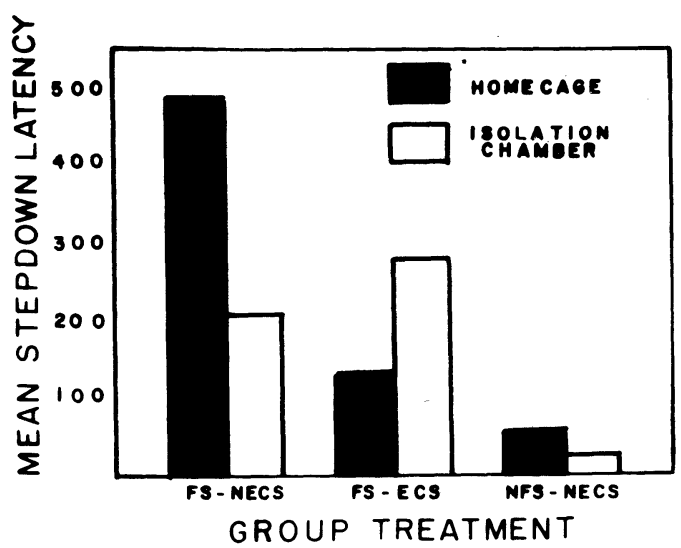

Figure 1. Mean stepdown latency as a function of shock treatment and posttreatment housing. The FS refers to footshock, the ECS to electroconvulsive shock, and $\mathrm{N}$ to the absence of shock treatment.

the grid floor also consisted of 5-mm-diam grids mounted in acrylic at $13-\mathrm{mm}$ intervals. A Harvard Instrument Company ac shock generator and scrambler (Model 3121) were used to deliver a $60-\mathrm{HZ} 1.6-\mathrm{mA}$ footshock through the floor of the apparatus. An A-615 B Lafayette Instrument Company shocker was used to deliver a $.5-\mathrm{sec} 60-\mathrm{HZ} 55-\mathrm{mA}$ ac ECS via modified alligator clips at tached to the subject's auricles.

The isolation chamber, a light-tight sound-attenuated compartment, consisted of an $18 \times 9 \times 17 \mathrm{~cm}$ (inside dimensions) flat-black plywood ( $1 / 4$-in.) box with a wire mesh floor and wood top. This wood box was enclosed on all sides by 5 -to-7-cm thick fiberglass batting and housed in a $29 \times 24$ $\mathrm{x} 27 \mathrm{~cm}$ zinc container which was located in an unlighted, undisturbed $2.4 \times .75 \times 2.6 \mathrm{~m}$ room.

\section{Procedure}

Prior to pretraining, subjects were handled 5 min daily for 2 days. On each of the following 5 pretraining days, rats, with earclips attached, were placed on the center platform of the stepdown apparatus. The time taken for the animal to place all feet on the grid floor (stepdown latency) was recorded to the nearest $.1 \mathrm{sec}$. Rats remained on the floor for $5 \mathrm{sec}$ and were then returned to their home cages. On the following training day, 20 subjects were assigned to each of three treatments. Immediately upon descent from the platform, subjects in the FS-ECS group received a 5-sec footshock followed immediately by ECS. Rats in the FS-NECS group received only the 5-sec footshock. The third group (NFS-NECS) received neither footshock nor ECS upon descent from the platform. Half of the subjects in each group were returned to home cages $(H)$ immediately after treatment. The remaining subjects were placed in the isolation chamber immediately after treatment and remained there for $1 \mathrm{~h}$. They were then returned to their home cages.

Twenty-four hours after training, the time taken to descend from the platform was again recorded. Subjects failing to descend from the platform within 10 min during this test were assigned a latency of $600 \mathrm{sec}$.

\section{RESULTS AND DISCUSSION}

A 2 by 3 factorial analysis of variance performed on the stepdown latencies of training revealed no significant group differences $(F=.93, \mathrm{df}=5 / 54)$. The mean test stepdown latency for each group is plotted in Figure 1. A 2 by 3 factorial analysis of variance performed on the test data showed a significant main effect of treatment $(\mathrm{F}=13.81, \mathrm{df}=2 / 54, \mathrm{p}<.0005)$ and a significant Treatment by Posttreatment Environment interaction $(\mathrm{F}=6.70, \mathrm{df}=2 / 54, \mathrm{p}<.005)$.

Individual comparisons indicated that ECS effectively disrupted retention performance when animals were returned to their home cages immediately after treatment. The FS-ECS-H and NFS-NECS-H groups did not differ from each other $(F=.94, \mathrm{df}=1 / 54)$, and both these groups differed significantly from the FS-NECS$\mathrm{H}$ group $(\mathrm{Fs} \geqslant 11.67, \mathrm{df}=1 / 54$, ps $<.005)$. Statistically, then, under the FS-ECS-H treatment condition, amnesia was complete.

Individual comparisons also indicated that sensory isolation is capable of disrupting retention performance. No significant difference in performance was found between the FS-NECS-I and FS-ECS-H groups $(F=.73$, $\mathrm{df}=1 / 54)$. Furthermore, the mean latency of the FS-NECS-I group was significantly lower than that of the FS-NECS-H group $(F=11.68, \mathrm{df}=1 / 54, \mathrm{p}<.05)$. However, the performance of the FS-NECS-I group also differed significantly from that of the NFS-NECS-I group $(F=4.75, \mathrm{df}=1 / 54, \mathrm{p}<.05)$, indicating that, statistically, some residual fear was present during testting in subjects isolated after the footshock-only treatment. Since the isolated subjects were detained in a small compartment for an hour following training, it is possible that the amnesic-like effect in the FS-NECS-I group is related to detention rather than to isolation per se. Such a detention-like effect has been reported by Robustelli and his associates (Robustelli, Geller, \& Jarvik, 1969; Robustelli \& Jarvik, 1968). Many of their procedures, however, involved detaining animals in the training apparatus or under conditions, e.g., lighting, that simulated the training conditions; hence, in their research, fear extinction and amnesia produced by detention and/or isolation cannot be clearly distinguished.

While no simple explanation of the amnesia produced by isolation and/or detention has been offered, the contextual cue hypothesis of Hinderliter, Webster, and Riccio (1975) adequately explains the phenomenon. Conscious animals undergoing sensory isolation immediately following formal training may well integrate isolation and training conditions and, hence, display amnesic-like behavior when contextual isolation cues are absent during testing. It should be noted that, in the absence of training, isolation should have no effect upon test performance. Accordingly, no significant difference in the mean test latencies of the two NFSNECS groups was found in the present study $(\mathrm{F}=.12$, $\mathrm{df}=1 / 54)$.

Sensory isolation, itself an amnesic agent, also had the paradoxical effect of attenuating ECS-produced RA. Although the test performance of the FS-ECS-I group differed significantly from that of the FS-NECS-H group $(F=6.49, \mathrm{df}=1 / 54, \mathrm{p}<.025)$, it also differed 
significantly from the performances of both NFS-NECS groups $(\mathrm{Fs} \geqslant 7.28$, df $=1 / 54$, ps $<.025)$, indicating a significant amount of fear influenced the performance of animals that underwent sensory isolation immediately following ECS. The finding that the mean test latency of the FS-ECS-I group was significantly higher than that of the FS-ECS-H group $(F=2.98, \mathrm{df}=1 / 54$, $\mathrm{p}<.05$, one-tailed) lends further support to this contention. Thus, the isolation effect reported by Calhoun et al. (1975) was replicated with rats not on a continuous light regimen, suggesting that novel lighting conditions were not a significant factor in the attenuation of RA in the Calhoun et al. (1975) and Peters et al. (1973) studies. More importantly, these results indicate that environmental manipulations within the first hour following the amnesic treatment alter the effect of ECS, suggesting that the critical events determining whether or not RA is produced may occur within that time period.

The finding that two amnesic agents administered consecutively produce less disruption of retention than the administration of a single agent indicates that amnesic agents do not bring to a halt the memory storage process (cf. McGaugh, 1966). If such were the case, administering the second agent should have no effect, or, possibly, should produce an even greater memory impairment. This finding does, however, lend support to the hypothesis that amnesic agents produce their effect by slowing the storage process (Misanin \& Hoover, 1971). According to this notion, the slowing of the memory process produced by so-called amnesic agents simply provides a greater opportunity for additional inputs into the system to interfere with the encoding of memory of the trained response, which, in turn, increases the probability of retrieval difficulty. Thus, in the present study, the reduction of input following ECS brought about by sensory isolation could explain the attenuation of amnesia in the FS-ECSI group. Alternatively, amnesic-agent treatments may simply alter events which are critical for retrieval. More specifically, if memory of the trained response becomes inadvertently linked with events associated with the amnesic-agent treatment (cf. Hinderliter et al., 1975), then treatments which help differentiate that linkage could attenuate RA. Sensory isolation following ECS should, accordingly, lead to fewer irrelevant stimulus events being simultaneously encoded with the memory trace of the training-treatment experience and, hence, help bring about this differentiation.

\section{REFERENCES}

Calmoun, K. S, Prewett, M. J., Peters, R. D., \& Adams, H. E. Factors in the modification by isolation of electroconvulsive shock-produced retrograde amnesia in the rat. Journal of Comparative and Physiological Psychology, 1975, 88, 373-377.

Hinderliter, C. F., Smith, S. L., \& Misanin, J. R. Effects of pretraining experience on retention of a passive avoidance task following ECS. Physiology and Behavior, 1973, 10, 671-675.

Hinderliter, C. F., Webster, T., \& Riccio, D. C. Amnesia induced by hypothermia as a function of the treatment-test interval and recooling in rats. Animal Learning \& Behavior, 1975, 3, 161-166.

Lewis, D. J., Miller, R. R., \& Misanin, J. R. Control of retrograde amnesia. Journal of Comparative and Physiological Psychology, 1968, 66, 48-52.

LewIS, D. J., Miller, R. R., \& Misanin, J. R. Selective amnesia in rats produced by electroconvulsive shock. Journal of Comparative and Physiological Psychology, $1969,69,136-140$.

McGaugh, J. L. Time dependent processes in memory storage. Science, 1966, 153, 1351-1358.

Misanin, J. R., \& Hoover, M. Recovery rate as a determinant of the amnesic-like effect of hypothermia. Physiology and Behavior, 1971, 6, 689-693.

Peters, R. D., Calhoun, K. S., \& Adams, H. E. Modification by environmental conditions of retrograde amnesia produced by ECS. Physiology and Behavior, 1973, 11, 889-892.

Riccio, D. C., Hodges, L. A., \& Randall, P. K. Retrograde amnesia produced by hypothermia in rats. Journal of Comparative and Physiological Psychology, 1968, 66, 618-622.

Robustelli, F., Geller, A., \& Jarvik, M. E. Combined action of two amnesic treatments. Communications in Behavioral Biology, 1969, 4, 221-229.

Robustelli, F., \& JaRvix, M. E. Retrograde amnesia from detention. Physiology and Behavior, 1968, 3, 543-547.

SMITH, S. L., \& Misanin, J. R. A reduction in ECS-produced amnesia through cooling. Psychonomic Science, 1972, 26, 21-22.

(Received for publication February 26, 1976.) 